\title{
Incidence of calcaneal spur in Indian population with heel pain
}

\author{
R. Kevin Lourdes*, Ganesan G. Ram
}

Department of Orthopaedics, Sri Ramachandra Medical University, Chennai, Tamil Nadu, India

Received: 12 August 2016

Accepted: 31 August 2016

\section{*Correspondence:}

Dr. R. Kevin Lourdes,

E-mail: Kevinlourdes5@gmail.com

Copyright: (C) the author(s), publisher and licensee Medip Academy. This is an open-access article distributed under the terms of the Creative Commons Attribution Non-Commercial License, which permits unrestricted non-commercial use, distribution, and reproduction in any medium, provided the original work is properly cited.

\begin{abstract}
Background: This is an observational study that was carried out to find out the incidence of calcaneal spur among Indian population with heel pain as it is one of the most commonest complaints of patients coming to out-patient departments.

Methods: Radiological assessment with 200 ankle lateral view x rays were taken for patients (100 male and 100 female) with complaints of heel pain.

Results: 118 out of 200 patients with heel pain had calcaneal spur either plantar or at achilles insertion or both of which $60 \%$ of them were women. Most common age group affected was 40-50 years.

Conclusions: Incidence of calcaneal spur in Indian population with heel pain is $59 \%$.
\end{abstract}

Keywords: Calcaneal spur, Heel pain, Indian population

\section{INTRODUCTION}

Heel pain is one of the most commonest complains with which a person presents to the out-patient department. ${ }^{1}$ The reasons for heel pain include Plantar fasciitis, Retrocalcaneal bursitis, atrophy of heel pad, achilles tendinitis, posttraumatic, (e.g., calcaneal fracture), haglund's deformity, enlarged calcaneal spur, degeneration of achilles tendon insertion. The other causes may be due to neurological conditions such as tarsal tunnel syndrome or entrapment of nerve to abductor digiti quinti, degenerative disc disease with radiation toward heel, systemic disease (e.g., reiter's syndrome, psoriatic arthritis), acute tear of plantar fascia and calcaneal apophysitis. ${ }^{2}$ Most of the heel pains will be associated with a spur. ${ }^{2}$ Calcaneal spurs can be of two types: Achilles and plantar. ${ }^{3}$ There are various studies regarding the incidence of calcaneal spur in various countries Australia (55.1\%), Thailand (15.5\%) and the Caucasian population $(15.7 \%){ }^{4-6}$ But not much studies have talked about its incidence among the Indian population. The aim of the study was to identify the incidence of patients with posterior heel pain showing calcaneal spur radiologically in Indian population.

\section{METHODS}

Prospective study done in Sri Ramachandra Medical University, Chennai, India from January 2016 to June 2016. The study population was the patients coming to orthopaedics out-patient department with complaints of posterior heel pain. Inclusion criteria were persistent of pain atleast for three months and pain score as per wong Bakers criteria more than 4 . No consent was needed as it was an observational study keeping the anonymity of the patient. A total of 200 ankle lateral view x-rays of 100 males and 100 females were taken. Patients who have had old ankle fractures, foot deformities or any other infective or traumatic pathology involving talar and sub talar joints were excluded from the study. Only symptomatic ankles were considered and patients below 18 years were excluded from the study. In case of patients with bilateral 
complaints only one side was randomly chosen. Radiological diagnosis of calcaneal spur was made and reported by radiologist at the rank of senior consultant, which was counterchecked by another senior consultant.

\section{RESULTS}

Out of the 200 ankles x-rays examined radiologically 118 of them had calcaneal spurs either at Achilles insertion or at plantar or both. Of the 118 patients with calcaneal spur $60 \%$ of them were female showing an increased preponderance in females compared to males. The most affected age group being 40-50 years of age. The incidence of spurs both in plantar and the site of insertion of Achilles were found to be $24 \%$ of the total calcaneal spurs. The results were tabulated in Table 1 and Table 2. The incidence of only plantar spur was found to be more when compared to achilles spur or both combined.

Table 1: Calcaneal spur in patients with posterior heel pain.

\begin{tabular}{|llll|}
\hline Gender & With spur & Without spur & Total patients \\
\hline Male & 48 & 52 & 100 \\
\hline Female & 70 & 30 & 100 \\
\hline
\end{tabular}

Table 2: Calcaneal spur as per age group and site.

\begin{tabular}{|lll|llll|}
\hline Age group & Plantar spur & \multicolumn{2}{l}{ Achilles spur } & Combined \\
\hline Years & Male & Female & Male & Female & Male & Female \\
\hline $20-30$ & 0 & 1 & 0 & 0 & 0 & 0 \\
\hline $30-40$ & 6 & 8 & 0 & 1 & 3 & 3 \\
\hline $40-50$ & 11 & 18 & 2 & 4 & 3 & 4 \\
\hline $50-60$ & 7 & 14 & 0 & 3 & 2 & 4 \\
\hline $60-70$ & 3 & 3 & 1 & 1 & 2 & 2 \\
\hline $70-80$ & 3 & 1 & 1 & 0 & & 3 \\
\hline
\end{tabular}

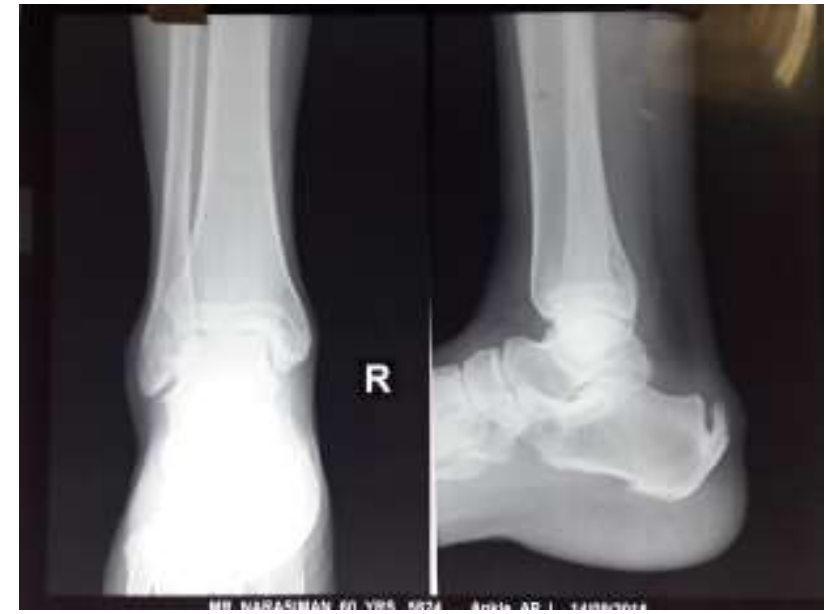

Figure 1: Calcaneal spur at achilles and plantar.

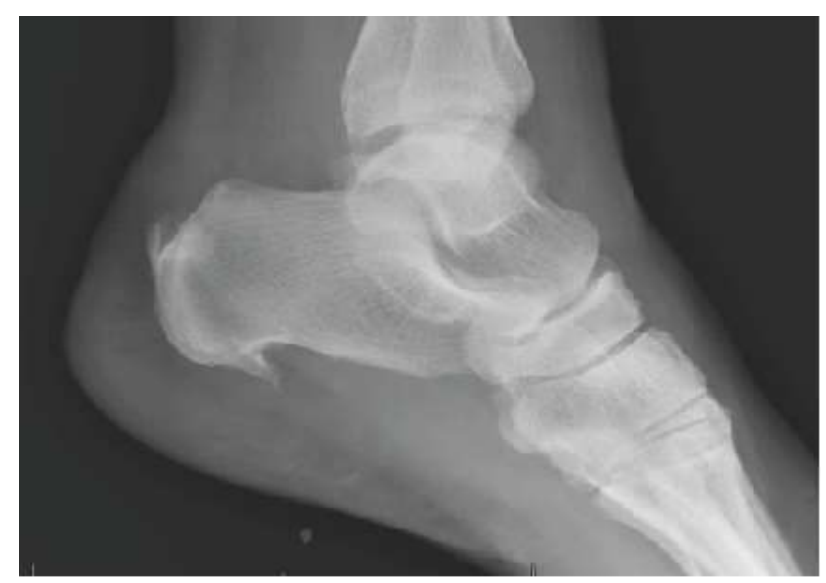

Figure 2: Plantar spur.

\section{DISCUSSION}

The spur formation is due to repetitive traction of the insertion of the plantar fascia into the calcaneum resulting in inflammation of reactive ossification of the enthesis. ${ }^{7}$ But it can also be attributed to be a result of vertical compression instead of traction. ${ }^{8}$ The study reveals that the incidence of calcaneal spur in patients presenting to the out-patient department with posterior heel pain to be around $59 \%$ of which $60 \%$ are female mostly affecting the age group between 40-50 years as shown in Figure 3. Plantar spur seems to be more common than spur occurring at the insertion of achilles. ${ }^{9}$ It is evident from the study that patients under 30 years of age do not show any presence of calcaneal spurs which could explain the spur formation to be part of a degenerative process resulting in osteophyte formation appearing in the form of bony growth. Its prevalence among women could be correlated with footwear, obesity and pregnancy resulting in excessive compressive forces acting at the calcaneum over a period of time.

The low incidence of any type of spur in age group less than 30 years suggested that spurs do take a long time to build up. This probably is because the enthesis organ dissipates the stress away from the bony insertion, this can explain why the pathological changes take place adjascent to the enthesis as well as at them. ${ }^{10}$ The absence of spurs in people below 20 years of age correlates with the common clinical observations that are rarely a feature of degenerative joint disease in young individuals. ${ }^{11}$ The proposed mechanical theory over the spur formation is not supported by this study as it shows that age group of people involved in maximum physical exercise from 20- 
40 seems to be little affected at the same time Cosentino et al has found that people involved in standing for long time as part of their professions were more likely to be affected. $^{12-15}$ Also a study reveals that chances of finding a calcaneal spur in normal population to be $15.5 \%$ and there are no clear cut relationship between the heel pain and the length, shape and direction of the calcaneal spur. ${ }^{16,17}$ So the change of lifestyle and footwear that can be brought about during early years of symptom could significantly alter the course of the disease preventing it from reaching degenerative stages as it is known to progress with age. The short comings of this study were that it involved only people living in and around Chennai and a small sample size.

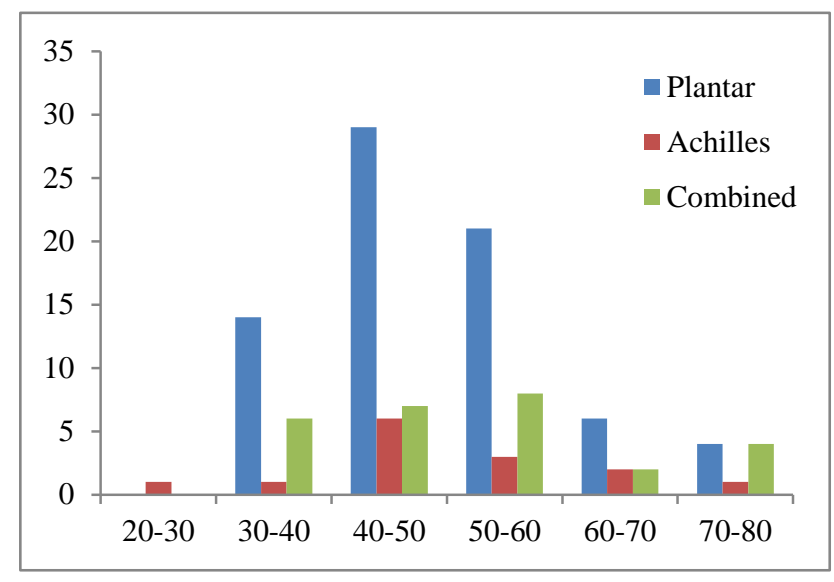

Figure 3: Schematic representation of calcaneal spur.

\section{CONCLUSION}

The incidence of calcaneal spur in south Indian population having posterior heel pain was $59 \%$.

Funding: No funding sources

Conflict of interest: None declared

Ethical approval: The study was approved by the institutional ethics committee

\section{REFERENCES}

1. Kwame EA, Kaiyu M. Heel pain: a systematic review. Chinese J Traumatology. 2015;18(3):164-9.

2. Thomas JL, Christensen JC, Kravitz SR. The diagnosis and treatment of heel pain: a clinical practice guideline revision. J Foot Ankle Surg. 2010;49:1-19.

3. Zhou B, Zhou Y, Tao X, Yuan C, Tang $\mathrm{K}$. Classification of calcaneal spurs and their relationship with plantar fasciitis. J Foot Ankle Surg. 2015;54(4):594-600.
4. Prichasuk S, Subhadrabandhu T. The relationship of pes planus and calcaneal spur to plantar heel pain. Clin Orthop Relat Res. 1994;306:92.

5. Reipert T, Drechsler T, Urban R, Schild H ,Mattern $\mathrm{R}$. The incidence, age dependence and sex distribution of the calcaneal spur. An analysisof X ray morphology in 1072 patients of the central European Population. Rofo. 1995;162;502-5.

6. Menz HB, Zammit GV, Landorf KB, Munteanu SE. Plantar calcaneal spurs in older people: longitudinal traction or vertical compression? J Foot Ankle Res. 2008;1;7.

7. Bergmann JN. History and mechanical control of heel spur pain. Clin Podiatr Med Surg. 1990;7(2):243-59.

8. Kumai T, Benjamin M. Heel spur formation and subcalcaneal enthesis of plantar fascia. J Rheumatol 2002;29(9):1957-64.

9. Toumi H, Davies R, Mazor M. Changes in prevalence of calcaneal spurs in men and women:a random population from a trauma clinic. Musculoskeletal Disorders. 2014

10. Benjamin $\mathrm{M}$, Moriggl B, Brenner E, Emery $\mathrm{P}$, McGonagle D, Redman S. The "enthesis organ" concept: why enthesopathies may not present as focal insertional disorders. Arthritis Rheum. 2004,50(10):3306-13.

11. Jacobson JA, Girish G, Jiang Y, Sabb B. Radiographic evaluation of arthritis: degenerative joint disease and variations. Radiology. 2008,248(3):737-47.

12. Schepsis AA, Jones H, Haas AL. Acilles tendon disorders in athletes. Amer $\mathrm{J}$ Sports Med. 2002;30:287-305.

13. Krahl H, Pieper HG, Quack G. Die Knochenhypertrophie als Trainingseffekt. Orthopade. 1995;24:441-5.

14. Tyrdal S, Finnanger AM. Osseous manifestations of handball goalies elbow. Scand J Med Sci Sports. 1999;9:92-7.

15. Cosentino R, Falsetti P, Manca S, Stefano R, Frati E, Frediani B, et al. Efficacy of extracorporeal shock wave treatment in calcaneal enthesophytosis. Ann Rheum Dis. 2001;60:1064-7.

16. Prichasuk S, Subhadrabandhu T. The relationship of pes planus and calcaneal spur tp plantar heel pain. Clin Orthop Relat Res. 1994;306:92-6.

17. Lu H, Gu G, Zhu S, Zhonghua W, Zhi KZ. Heel pain and calcaneal spurs. Int J Appl Basic Med Res. 1996:34:294-6.

Cite this article as: Lourdes RK, Ram GG. Incidence of calcaneal spur in Indian population with heel pain. Int J Res Orthop 2016;2:174-6. 